\title{
Is the Amount of Coronary Perivascular Fat Related to Atherosclerosis?
}

\section{KRALOVA LESNA ${ }^{1}$, Z. TONAR ${ }^{6}$, I. MALEK ${ }^{2}$, J. MALUSKOVA $^{3}$, L. NEDOROST ${ }^{6}$,

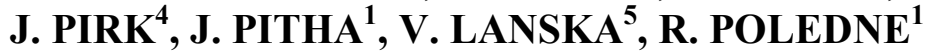

${ }^{1}$ Centre for Experimental Medicine, Laboratory for Atheroslerosis Research, Institute for Clinical and Experimental Medicine, Prague, Czech Republic, ${ }^{2}$ Cardiology Department, Institute for Clinical and Experimental Medicine, Prague, Czech Republic, ${ }^{3}$ Clinical and Transplant Pathology Department, Institute for Clinical and Experimental Medicine, Prague, Czech Republic, ${ }^{4}$ Cardiovascular Surgery Department, Institute for Clinical and Experimental Medicine, Prague, Czech Republic, ${ }^{5}$ Statistical Department, Institute for Clinical and Experimental Medicine, Prague, Czech Republic, ${ }^{6}$ Department of Histology and Embryology and Biomedical Centre, Faculty of Medicine in Pilsen, Charles University in Prague, Pilsen, Czech Republic

Received July 17, 2015

Accepted July 31, 2015

\begin{abstract}
Summary
Interesting and stimulating data about the effect of the perivascular adipose tissue size on atherogenesis are based mainly on CT findings. We studied this topic by directly analyzing perivascular adipose tissue in explanted hearts from patients undergoing transplantation. Ninety-six consecutive patients were included, including 58 with atherosclerotic coronary heart disease (CHD) and 38 with dilation cardiomyopathy (DCMP). The area of perivascular fat, area of the coronary artery wall, and ratio of CD68-positive macrophages within the perivascular fat and within the vascular wall were quantified by immunohistochemistry. There was no significant difference in the perivascular adipose tissue size between the two groups. Nevertheless, there was a significantly higher number of macrophages in the coronary arterial wall of $\mathrm{CHD}$ patients. In addition, we found a close relationship between the ratio of macrophages in the arterial wall and adjacent perivascular adipose tissue in the CHD group, but not in the DCMP group. According to our data interaction between macrophages in the arterial wall and macrophages in surrounding adipose tissue could be more important mechanism of atherogenesis than the size of this tissue itself.
\end{abstract}

\section{Key words}

Perivascular fat - Macrophages • Coronary artery • Atherosclerosis

\section{Corresponding author}

I. Králová Lesná, Institute for Clinical and Experimental Medicine, Centre for Experimental Medicine, Laboratory for Atherosclerosis Research, Videnska 1958/9, 14021 Prague, Czech Republic. E-mail: ivka@ikem.cz

\section{Introduction}

Although the relationship between visceral adiposity and cardiovascular disease was described more than 70 years ago (Vague 1947), the mechanisms of the influence of adipose tissue on coronary atherosclerosis is not fully understood. Numerous recent reviews describe anatomic differences, the participation of other organs and the different obesity consequences (for example Bays 2011). Starting from a hunting term syndrome $X$ (Reaven 1994) to the recent summary of the key player - adipose tissue resident immune cells (Schipper et al. 2012) - both represent a long-lasting way of understanding the process of adiposopathy as it relates to coronary atherosclerosis. The negative influence of the visceral obesity accelerates atherogenesis by metabolic dyslipoproteinemia (Adiels et al. 2006), lipotoxicity of free fatty acids (Bays et al. 2004), and changes in the endocrine function of adipose tissue (Kougias et al. 2005) and innate as well as adaptive immunity (for review see Schipper et al. 2012) regulated 
by adipose tissue resident immune cells.

The next topic was opened by the analysis of periaortal fat depots in relation to aortic calcification from analysis of more than one thousand participants in the Framingham Offspring Study (Lehman et al. 2010). Prior to this important study, several other groups tried to measure the local effect of perivascular adipose tissue on vascular wall reactivity. Whereas no effect on endothelial dysfunction was found in the brachial artery in men (Rittig et al. 2008), an in vitro study of vessel wall reactivity of the porcine coronary artery was described (Reifenberger et al. 2007). Perivascular adipose tissue differs from other adipose tissue and consists not only of the white adipocytes, it also contains brown adipose tissue (Szasz and Webb 2012). This adipocytes mixture, as well as its vascularization and innervation, vary by location (Chatterjee et al. 2009). It is very probable that so called ectopic fat not only plays an important role in the development of insulin resistance, it has a proatherogenic metabolic role from its independent interaction with adipose tissue surrounding the artery. More recently, the interplay between the arterial wall and perivascular adipose tissue has been studied with both atheroprotecting (Margaritis et al. 2013) and atherostimulating (Tian et al. 2013) effects of perivascular adipose tissue.

It is evident that perivascular adipose tissue releases, in addition to free fatty acids, many hormones and hormone-like substances (for a summary see Szasz and Webb 2012). Although adipocytes constitute the majority of cells in perivascular adipose tissue, the other cells, namely monocytes/macrophages and T-lymphocytes, can produce biologically active molecules. The cross-talk between adipocytes and these infiltrating immune cells might play a critical role in pathological conditions (Suganami et al. 2005), namely in atherosclerosis.

At least two basic functional phenotypes of macrophages, i.e. M1 classically activated proinflammatory macrophages and M2 alternatively activated anti-inflammatory macrophages have been mentioned (Italiani and Boraschi 2014), but there is no clear method to distinguish them. Furthermore, although some $\mathrm{CD}$ markers of the M2 subpopulation have been identified (CD163 and CD206), the M1 subpopulation determining $\mathrm{CD}$ markers is still unclear.

The aim of presented study was to analyze the relationship between coronary artery disease and the amount of perivascular coronary fat, coronary artery diameter, and total macrophage content both in the artery wall and in the adipose tissue using an extensive transplantation program.

\section{Methods}

\section{Patients}

Ninety-six consecutive patients were included in the study differing by different pathophysiology of heart failure, either with advanced atherosclerosis - coronary heart disease $(\mathrm{CHD})(\mathrm{n}=58)$ or dilatation cardiomyopathy (DCMP) $(n=38)$. Body weight was measured on the day of transplantation. The body mass index (BMI) was calculated as BMI $=$ weight $(\mathrm{kg}) /$ height $(\mathrm{m})^{2}$.

\section{Explanted hearts}

Subjects were enrolled $(n=64)$ in the period between November 2012 and April 2014. Two independent pathologists were responsible for heart sample handling. The first pathologist determined the heart weight and dissected samples of the heart and fixed them within a $24 \mathrm{~h}$ period after explanation in the pathology department of our Institute. It is necessary to stress that a second pathologist from another institute performed objective morphologic and immunohistochemic measurement. He was completely blinded to clinical status of the patients and independent of the transplantation team.

From each heart, two samples of the left anterior descending (LAD) coronary artery were collected, consisting of a proximal segment and distal segment together with the surrounding adipose tissue between the epicardial mesothelium and myocardium. The lateral borders of the tissue blocks were cut to preserve the adipose tissue within the same distance as the thickness of the epicardium layer. The dimensions of the tissue blocks were standardized to a surface area of $10 \times 10 \mathrm{~mm}$ and to a maximum depth of $10 \mathrm{~mm}$. Due to the variable level of epicardial fat, the final depth of the tissue blocks reflected the local epicardial fat surrounding the coronary arteries in every patient under study. Samples were fixed using $4 \%$ buffered formalin; after at least $24 \mathrm{~h}$, they were embedded into paraffin blocks.

\section{Histology and immunohistochemistry}

The second pathologist, who was completely blinded to the history of samples, was responsible for immunohistochemistry and quantitative histology. The quantification of the cross-sectional area of coronary 
Table 1. The main characteristics of CHD and DCMP patients who underwent transplantation.

\begin{tabular}{lccc}
\hline & CHD & DCMP & Significance \\
\hline Number of subjects & 58 & 38 & \\
Age (years) & $55.9( \pm 8.6)$ & $48.6( \pm 12.3)$ & $\mathrm{p}<0.01$ \\
Total cholesterol $(\mathrm{mmol} / \mathrm{l})$ & $4.16( \pm 1.07)$ & $3.91( \pm 1.32)$ & $\mathrm{n} . \mathrm{s}$. \\
HDL cholesterol $(\mathrm{mmol} / \mathrm{l})$ & $0.92( \pm 0.30)$ & $0.91( \pm 0.37)$ & $\mathrm{n} . \mathrm{s}$. \\
Triglycerides $(\mathrm{mmol} / \mathrm{l})$ & $1.53( \pm 0.70)$ & $1.13( \pm 0.51)$ & $\mathrm{p}<0.002$ \\
BMI $\left({\left.\mathrm{kg} \times \mathrm{m}^{-2}\right)}^{25.19( \pm 3.54)}\right.$ & $24.20( \pm 4.34)$ & $\mathrm{n} . \mathrm{s}$. \\
\hline
\end{tabular}

Mean values \pm SD.

artery (CA) wall and cross-section area of perivascular adipose tissue (in $\mathrm{mm}^{2}$ ) was based on three sections stained with Verhoeff's hematoxylin (Hematoxylin monohydrate certistain for microscopy, Cat. No. 1.15938.0100, Merck, Darmstadt, Germany) and green trichrome (Fuchsin acid certistain for microscopy, Cat. No. 1.05231.0025, Merck; Eosin yellowish, Cat. No. 70088431, Merck; Orange G Certistain, Cat. No. 1.15925.0025, Merck; Light green SF yellowish certistain, Cat. No. 1.15941.0025, Merck). The whole histological slides were scanned and the cross-sectional area of the CA and epicardial adipose tissue was quantified using the stereological point grid technique.

The quantification of macrophages was based on the positivity of CD68 by immunohistochemistry. Monoclonal mouse anti-human CD68 antibody (clone KP1; Cat. No. M0814, DakoCytomation, Glostrup, Denmark) was used as the primary antibody followed by incubation with secondary antibody and avidin-biotin peroxidase complex (Vectra Stain ABC Kit, Cat. No. PK-4000, Vector Laboratories Inc; Burlingame, USA). The background tissue was stained with Gill's hematoxylin (Cat. No. SPC-019-01, Dr. Kulich Pharma, Hradec Kralove, Czech Republic). As CD68 may also be expressed by neutrophilic and basophilic granulocytes and natural killer cells, the differentiation of macrophages from these cells was based also on the macrophage size and characteristic nuclear and cytoplasmic morphology.

From each patient, a series of six image fields was sampled (the mean was used for analysis) within the wall of the LAD artery in a systematic uniform random manner using a $40 \times$ microscope objective. Another series of six image fields (40× objective) was sampled from the adjacent adipose tissue. Using the stereological point grid technique, the mean area fraction of CD68-positive macrophages was quantified within the LAD wall and within the epicardial fat as a dimensionless ratio.

\section{Biochemistry}

The total cholesterol, triglycerides and HDL cholesterol fraction were determined from fasting blood samples obtained immediately before operation (prior to anesthesia) by the enzymatic method HoffmanLaRoche (Switzerland). The concentration of the HLD fraction was analyzed after the precipitation of apoprotein B containing particles with the phosphotungstate method. These data were analyzed using autoanalyzer Cobas Mira+ HoffmanLaRoche (Switzerland).

\section{Ethics aspects}

The local Ethics Committee approved the study protocol according to the Helsinki declaration of 1975 as revised in 2000 and study was conducted in accordance with the approved protocol. All participants were informed about the purpose of the study and the provided written informed consent prior to enrolment in the study.

\section{Statistics}

Data are reported as the mean value $\pm \mathrm{SD}$ and differences are analyzed using the Wilcoxon or KruskalWallis tests. Triglycerides concentration was analyzed after logarithmic transformation. The Spearman correlation coefficient was calculated to evaluate the relationship between the macrophage contents in the arterial wall and adipose tissue.

\section{Results}

The mean age of CHD subjects was higher than of the DCMP group $(p<0.01$, Table 1$)$ and the proportion of both sexes was similar $(16.1 \%$ of women were included in the CHD group and $21.2 \%$ in the DCMP 
Table 2. Morphology of the coronary artery (CA) and perivascular adipose tissue (PVAT).

\begin{tabular}{|c|c|c|c|}
\hline Proximal part & CHD & DCMP & Significance \\
\hline Area of perivascular adipose tissue $\left(\mathrm{mm}^{2}\right)$ & $96.4( \pm 83.1)$ & $91.1( \pm 77.1)$ & n.s. \\
\hline Area of $C A\left(\mathrm{~mm}^{2}\right)$ & $10.9( \pm 5.1)$ & $7.7( \pm 3.7)$ & $\mathrm{p}<0.002$ \\
\hline $\begin{array}{l}\text { Area fraction of CD68+cells } \times 10^{2} \text { in the } \\
\text { perivascular adipose tissue }\end{array}$ & $0.53( \pm 0.76)$ & $0.31( \pm 0.2)$ & n.s. \\
\hline Area fraction of $C D 68+$ cells $\times 10^{2}$ in the $C A$ wall & $1.27( \pm 1.69)$ & $0.26( \pm 0.28)$ & $\mathrm{p}<0.001$ \\
\hline \multicolumn{4}{|l|}{ Distal part } \\
\hline Area of perivascular adipose tissue $\left(\mathrm{mm}^{2}\right)$ & $63.91( \pm 48.3)$ & $52.5( \pm 46.7)$ & n.s. \\
\hline Area of $C A\left(\mathrm{~mm}^{2}\right)$ & $7.24( \pm 3.58)$ & $4.93( \pm 2.81)$ & $\mathrm{p}<0.001$ \\
\hline $\begin{array}{l}\text { Area fraction of CD68+ cells } \times 10^{2} \text { in the } \\
\text { perivascular adipose tissue }\end{array}$ & $0.47( \pm 0.30)$ & $0.54( \pm 0.26)$ & n.s. \\
\hline Area fraction of $C D 68+$ cells $\times 10^{2}$ in the $C A$ wall & $1.50( \pm 1.98)$ & $0.55( \pm 0.69)$ & $\mathrm{p}<0.002$ \\
\hline
\end{tabular}

Mean values $\pm \mathrm{SD}$.

group). The BMI did not significantly differ between the groups. When all transplanted patients were analyzed together according their body weight change during last year before transplantation, the area of PVAT decreased for those with a body weight decrease of more than $2 \mathrm{~kg}$ $\left(38.4 \pm 23.5 \mathrm{~mm}^{2}\right)$ compared with the group with no change of body weight ( $\pm 2 \mathrm{~kg}, 44.5 \pm 10.5 \mathrm{~mm}^{2}$ ), and the highest value was for a body weight increase of more than $2 \mathrm{~kg}\left(54.6 \pm 30.0 \mathrm{~mm}^{2}\right)$. Although the mean differences were substantial, the trend in three groups did not reach statistical significance. No differences in total cholesterol were observed. HDL cholesterol was also almost identical in both compared groups. The fasting triglyceride concentrations were significantly higher in CHD patients $(1.53 \pm 0.70)$ compared to the DCMP group $(1.13 \pm 0.51)$, but the mean values were lower in both men and women compared to a representative sample of the same population (Cifkova et al. 2010).

The main finding regarding the aim of our study was that the cross-sectional area of perivascular fat surrounding the coronary artery of CHD patients was not different compared to DCMP subjects. This was valid for both the proximal and distal samples (Table 2). The area fraction of macrophages in the PVAT did not differ between the CHD and DCMP groups, although there was a tendency for a higher value in the CHD group in the proximal part $\left(0.53\right.$ vs. $\left.0.31 \mathrm{~mm}^{2}\right)$ that in the DCMP group. Nevertheless, when the ratios of macrophages in the coronary artery and in the corresponding adjacent adipose tissue were compared between the CHD and
DCMP groups, there were highly significant differences. Although there was no significant association of ratio of macrophages in PVAT with ration of macrophages in artery wall in the proximal part $(\mathrm{p}=0.07)$ or distal part $(p=0.38)$ of coronary arteries in the DCMP group, this association was found to be rather strong in the CHD group ( $\mathrm{p}<0.002$ proximal and $\mathrm{p}<0.005$ distal part, Fig. 1, only data of the distal part are presented). Although there is no relationship in the expected transport of some types of inflammatory cells between adjacent adipose tissue to the coronary artery (or an indirect influence) in patients with dilated cardiomyopathy, there is a highly significant relationship between these two tissues in patients with coronary atherosclerosis. As might be expected, the ratio of macrophages within the artery wall was substantially greater in the CHD group than in the DCMP group $\left(1.27 \pm 1.69\right.$ vs. $0.26 \pm 0.28 \times 10^{2} ; \mathrm{p}<0.001$ in the proximal segment and $1.5 \pm 1.98$ vs. $0.55 \pm 0.69 \times 10^{2} ; \mathrm{p}<0.002$ in the distal segment).

Additional finding of interest was that the crosssectional areas of both the proximal and distal segments of the coronary artery were larger in patients with CHD compared to patients with cardiomyopathy, representing a more than $40 \%$ increase $\left(10.9 \pm 5.1\right.$ vs. $7.7 \pm 3.7 \mathrm{~mm}^{2}$; $\mathrm{p}<0.002$ in the proximal part and $7.24 \pm 3.58$ vs. $4.93 \pm 2.81$ $\mathrm{mm}^{2} ; \mathrm{p}<0.001$ in the distal part of the coronary artery). Regarding this finding, there was no significant difference in the heart weight even though the mean weight in CHD patients was $10 \%$ higher. 

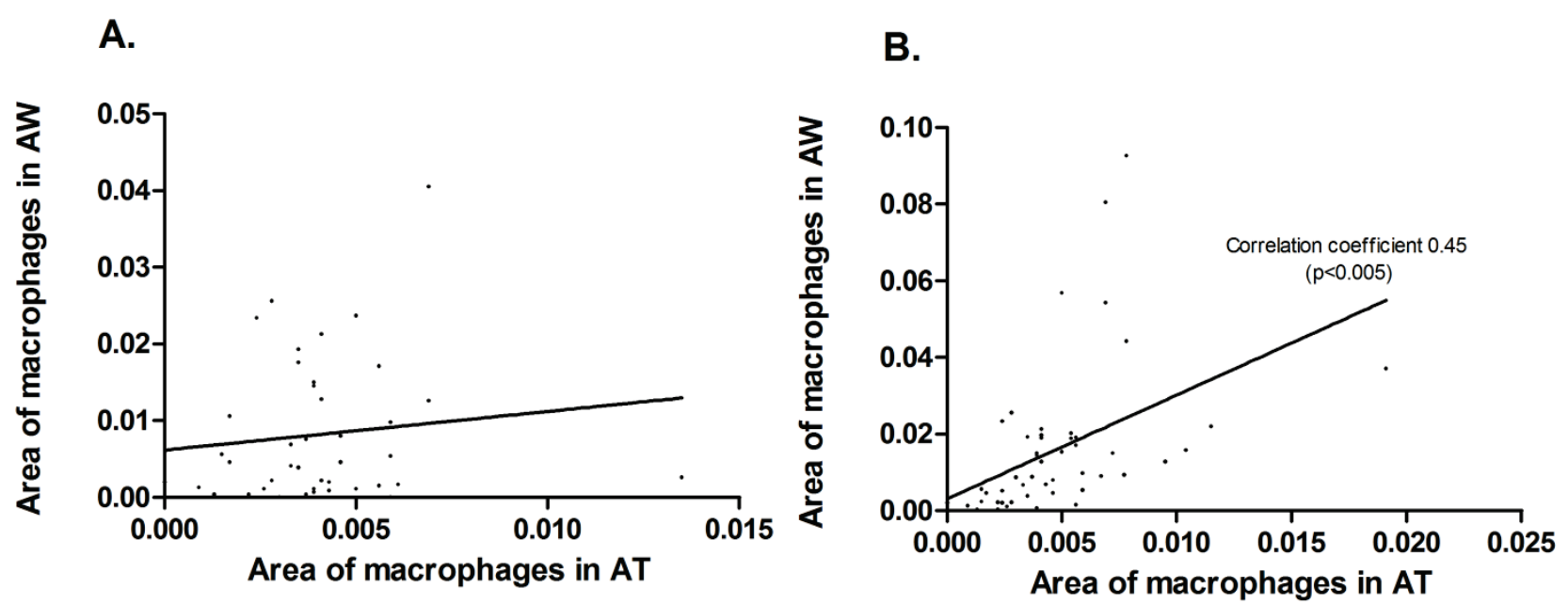

Fig. 1. Relationships between the macrophage surface area of the coronary artery wall (AW) with the area fraction of macrophages in the perivascular adipose tissue (AT) in the DCMP (A) and CHD (B) groups (data of samples of the distal part).

\section{Discussion}

Some recent data have documented a possible direct relationship between the size of perivascular fat and the progression of atherosclerosis (Greif et al. 2009, Verhagen et al. 2012). Inspired by these data we tried to reproduce the results obtained by the CT method via direct analysis of the perivascular adipose tissue in explanted hearts obtained during the transplantation of two groups of patients with different causes of heart failure - ischemic heart disease and dilated cardiomyopathy. As the main result of our study we did not find any differences in the size of PVAT between these two groups. However, we have found strong evidence, that in the process of atherosclerosis, the interaction of perivascular adipose tissue and arterial wall is of importance. This evidence is based on observed strong relationship of ratio of macrophages in PVAT with ratio of macrophages in artery wall in CHD but not in DCMP group.

The direct local effect of perivascular adipose tissue on the development of atherosclerosis in the arterial wall has been discussed repeatedly over recent years (see reviews Iacobellis et al. 2008, Ouwens et al. 2010). This approach was stimulated by numerous data presented in the last decade of the $20^{\text {th }}$ century, which describe the new active role of adipose tissue in the risk of insulin resistance and, consequently, the indirect effect on cardiovascular disease (Adiels et al. 2006).

In our hands, it was very difficult to analyze the size of the perivascular adipose tissue by dual source CT methods because it was impossible to delineate the vascular wall adventitia from surrounding perivascular fat in explanted hearts. Therefore, we tried to use an alternative approach to analyze the vascular wall and perivascular tissue size by direct analysis of samples obtained from explanted heart of patients with either CHD or DCMP.

We were unable to confirm the direct effect of perivascular adipose tissue size on coronary atherosclerosis that was reported by others (Greif et al. 2009). When direct measurement of the size of perivascular adipose tissue surrounding the left coronary artery was performed, there were no significant differences in the perivascular fat size between explanted hearts with coronary atherosclerosis compared with hearts with non-atherosclerotic disease, either in the proximal or in the distal parts of the arterial tree. It is probable that the size of PVAT is partially influenced by the general health status prior to transplantation. Although the mean value of the area of PVAT differs more than $50 \%$ when subjects with cachexia and weight increase are compared, this analysis did not reach statistical significance because reliable data were only available in patients treated at our Institute long before transplantation.

The direct effect of the adipose tissue size on CHD pathogenesis was also questioned by the Britton study (Britton et al. 2012), where the size of perivascular fat in the thoracic aorta had a close relationship to different risk factors of cardiovascular disease in a large population in the Framingham Heart Offspring Study. This does not mean that there is no effect unrelated to the size of adipose tissue surrounding the coronary artery. In fact, a recently published review by Owen et al. (2014), analyzing and explaining the vasoconstrictive and vasodilatative effects of perivascular adipose tissue 
produced substances, documented a certain effect in different experimental models.

As an additional finding, the cross-sectional area of coronary arteries was clearly larger in the CHD group compared with the DCMP. This finding might be explained by compensatory enlargement of coronary arteries caused by the process of atherosclerosis as already described (Glagov et al. 1987). Because we did not find any relationship between the coronary artery size of explanted hearts and heart weight in either group we did not consider this finding to be related to the size of the heart.

Regarding other important risk factors under study, when two groups of patients were compared, there was no significant difference in the age at the time of transplantation. Surprisingly, both groups displayed normal BMIs in spite of the fact that the prevalence of overweight and obesity in Czech population is high, and the average BMI, by age for transplanted patients is much higher; in addition, in both groups under study, the mean value of total cholesterol was much lower compared to a representative sample of the Czech population (Cifkova et al. 2010). This could be partly due to the systematic care provided to patients before transplantation including lifestyle recommendations and medical therapy focused on dyslipidemia, but it could be most likely also due to the general physical status of some patients before transplantation (cachexia). Regarding absence of differences in the total cholesterol concentration between the CHD and DCMP groups, but it could be explained by the fact that almost $90 \%$ of CHD patients were treated with statins for a long period before transplantation, whereas only $30 \%$ of patients in the DCMP group were treated with statins. This is most likely the same reason why we did not find any difference in the concentration of HDL cholesterol.

A significant difference was found in the fasting concentration of triglycerides. It was higher in patients with coronary heart disease compared to the DCMP group. This is another example of the possible atherogenic effect of triglyceride-rich lipoproteins, which is manifested in spite of the high frequency of hypolipidemic therapy by statins (for a review see Boren et al. 2014). It is tempting to speculate that different risk factors of atherosclerosis might be more expressed over a longer time period before transplantation in CHD patients. This atherogenic effect might include not only a high LDL concentration (frequently treated by statins) but also the relatively frequent atherogenic effect of remnants of triglyceride-rich lipoproteins, which can be detected at a nonfasting triglyceride concentration (Boren et al. 2014).

The area of macrophages in the coronary arteries of CHD patients could be expected to be significantly higher than the coronary arteries of patients with DCMP. Our results are in agreement with the morphology study by Verhagen et al. (2012), which analyzed 16 postmortem hearts in patients with CHD. This documents the central role of invading macrophages in the progression of the atherosclerotic process in the artery wall. Our results did not show a significant difference in the total macrophage area in the perivascular adipose tissue when patients with CHD and DCMP were compared, in spite of the $70 \%$ increase in the proximal parts of arteries in the CHD group. This might be influenced by the very high variability of fractions in the macrophage surface areas, especially in the CHD group. Most surprising is the substantially different relationship of macrophages in the perivascular adipose tissue and in the corresponding arterial wall. A close relationship was found in the group with atherosclerosis, and no such relation in dilatation cardiomyopathy group indicates the close interplay between these cells in atherosclerosis progression.

Keeping in mind problems of findings based on simple correlation which not always prove causality we suggest two alternatives to describe the proposed mechanism. Either macrophage flux from the PVAT to the arterial wall in CHD patients is stimulated or atherosclerotic patients' PVAT produces low molecular substances that penetrate to the artery, which drives certain trapping of monocytes coming to the artery wall from the artery lumen. It might be also speculated that some of the macrophages attracted by perivascular adipose tissue-borne inflammatory signals end up within the arterial wall and colonize it. It is interesting that monocyte migration, triggering vascular smooth muscle proliferation and migration is apparently regulated by the same cytokine, MCP-1 (Manka et al. 2014), whose abundant source was documented in inflamed adipose tissue. The high expression of adhesion molecules in adipose tissue also documents a possible direct effect of adipose tissue on initial process of monocyte infiltration (Bosanska et al. 2010). Additionally, a genetically determined variety of properties and behaviors of monocytes/macrophages might be an important factor. Our older data demonstrated that there are different numbers of CD14 receptors (innate immunity receptor for bacterial pro-inflammatory signals) in myocardial infarct 
survivors in relation to genetic polymorphisms at this locus (Hubacek et al. 1999).

Although numerous studies focusing on coronary perivascular adipose tissue inflammation have been published, only some include direct quantification of macrophages within the perivascular adipose tissue of coronary arteries. In his study, Hirata et al. (2011) found enhanced macrophage infiltration within the epicardial adipose tissue in CHD subjects compared with subjects who underwent valve replacement therapy. One possible explanation for this discrepancy could be that the total adiposity, taken as a mean BMI in their participants, was substantially lower $\left(23.8 \mathrm{~kg} / \mathrm{m}^{2}\right.$ in the CHD group and $22.9 \mathrm{~kg} / \mathrm{m}^{2}$ in the non-CHD group) than in our group. It has been documented that perivascular adipose tissue size is related to other risk factors of $\mathrm{CHD}$, including the BMI (Britton et al. 2012). Increased macrophage infiltration into the coronary PVAT was also demonstrated by Verhagen et al. (2012), but it is necessary to stress that this detailed post-mortem analysis included only a very limited number of individuals.

Our results do not mean that the proportions of proatherogenic and atheroprotective immune cells are the same because we did not further characterize the infiltrating macrophages to distinguish between the macrophage subpopulation, i.e. M1 and M2 macrophages. In the aforementioned study (Hirata et al.
2011), the authors also demonstrated the correlation of the M1/M2 ratio with the CHD stage. Further studies aimed at specifying the macrophage phenotypes in more detail, and those trying to analyze the relationship of different phenotypes to proinflammatory or antiinflammatory macrophages in the arterial wall and adjacent adipose tissue, would greatly contribute to the current knowledge in this field. Unfortunately, this detailed analysis is not currently feasible because no methodology clearly distinguishes between M1 and M2 macrophages using an immunohistochemistry method. This issue is a matter of ongoing debate (Mills 2012).

One limitation of the study is the assumption that all dissected samples have a similar total volume. This need not be really true, but this variation should be the same in both compared groups. Furthermore, our morphological data were obtained after a certain period from the explantation of the hearts, and dissected samples were fixed using formalin solution, but handling was identical for both groups.

\section{Conflict of Interest}

There is no conflict of interest.

\section{Acknowledgements}

This work was supported by a grant NT-14009/3 of the Ministry of Health of the Czech Republic.

\section{References}

ADIELS M, TASKINEN MR, PACKARD C, CASLAKE MJ, SORO-PAAVONEN A, WESTERBACKA J, VEHKAVAARA S, HAKKINEN A, OLOFSSON SO, YKI-JARVINEN H, BOREN J: Overproduction of large VLDL particles is driven by increased liver fat content in man. Diabetologia 49: 755-765, 2006.

BAYS H, MANDARINO L, DEFRONZO RA: Role of the adipocyte, free fatty acids, and ectopic fat in pathogenesis of type 2 diabetes mellitus: peroxisomal proliferator-activated receptor agonists provide a rational therapeutic approach. J Clin Endocrinol Metab 89: 463-478, 2004.

BAYS HE: Adiposopathy is "sick fat" a cardiovascular disease? J Am Coll Cardiol 57: 2461-2473, 2011.

BOREN J, MATIKAINEN N, ADIELS M, TASKINEN MR: Postprandial hypertriglyceridemia as a coronary risk factor. Clin Chim Acta 431: 131-142, 2014.

BOSANSKA L, MICHALSKY D, LACINOVA Z, DOSTALOVA I, BARTLOVA M, HALUZIKOVA D, MATOULEK M, KASALICKY M, HALUZIK M: The influence of obesity and different fat depots on adipose tissue gene expression and protein levels of cell adhesion molecules. Physiol Res 59: 79-88, 2010.

BRITTON KA, PEDLEY A, MASSARO JM, CORSINI EM, MURABITO JM, HOFFMANN U, FOX CS: Prevalence, distribution, and risk factor correlates of high thoracic periaortic fat in the Framingham Heart Study. $J$ Am Heart Assoc 1: e004200, 2012.

CHATTERJEE TK, STOLL LL, DENNING GM, HARRELSON A, BLOMKALNS AL, IDELMAN G, ROTHENBERG FG, NELTNER B, ROMIG-MARTIN SA, DICKSON EW, RUDICH S, WEINTRAUB NL: Proinflammatory phenotype of perivascular adipocytes: influence of high-fat feeding. Circ Res 104: 541-549, 2009. 
CIFKOVA R, SKODOVA Z, BRUTHANS J, ADAMKOVA V, JOZIFOVA M, GALOVCOVA M, WOHLFAHRT, P, KRAJCOVIECHOVA A, POLEDNE R, STAVEK P, LANSKA V: Longitudinal trends in major cardiovascular risk factors in the Czech population between 1985 and 2007/8. Czech MONICA and Czech post-MONICA. Atherosclerosis 211: 676-681, 2010.

GLAGOV S, WEISENBERG E, ZARINS CK, STANKUNAVICIUS R, KOLETTIS GJ: Compensatory enlargement of human atherosclerotic coronary arteries. $N$ Engl J Med 316: 1371-1375, 1987.

GREIF M, BECKER A, VON ZIEGLER F, LEBHERZ C, LEHRKE M, BROEDL UC, TITTUS J, PARHOFER K, BECKER C, REISER M, KNEZ A, LEBER AW: Pericardial adipose tissue determined by dual source CT is a risk factor for coronary atherosclerosis. Arterioscler Thromb Vasc Biol 29: 781-786, 2009.

HIRATA Y, TABATA M, KUROBE H, MOTOKI T, AKAIKE M, NISHIO C, HIGASHIDA M, MIKASA H, NAKAYA Y, TAKANASHI S, IGARASHI T, KITAGAWA T, SATA M: Coronary atherosclerosis is associated with macrophage polarization in epicardial adipose tissue. J Am Coll Cardiol 58: 248-255, 2011.

HUBACEK JA, ROTHE G, PIT'HA J, SKODOVA Z, STANEK V, POLEDNE R, SCHMITZ G: C(-260)-->T polymorphism in the promoter of the $\mathrm{CD} 14$ monocyte receptor gene as a risk factor for myocardial infarction. Circulation 99: 3218-3220, 1999.

IACOBELLIS G, GAO YJ, SHARMA AM: Do cardiac and perivascular adipose tissue play a role in atherosclerosis? Curr Diab Rep 8: 20-24, 2008.

ITALIANI P, BORASCHI D: From monocytes to M1/M2 macrophages: phenotypical vs. functional differentiation. Front Immunol 5: 514, 2014.

KOUGIAS P, CHAI H, LIN PH, YAO Q, LUMSDEN AB, CHEN C: Effects of adipocyte-derived cytokines on endothelial functions: implication of vascular disease. J Surg Res 126: 121-129, 2005.

LEHMAN SJ, MASSARO JM, SCHLETT CL, O'DONNELL CJ, HOFFMANN U, FOX CS: Peri-aortic fat, cardiovascular disease risk factors, and aortic calcification: the Framingham Heart Study. Atherosclerosis 210: 656-661, 2010.

MANKA D, CHATTERJEE TK, STOLL LL, BASFORD JE, KONANIAH ES, SRINIVASAN R, BOGDANOV VY, TANG Y, BLOMKALNS AL, HUI DY, WEINTRAUB NL: Transplanted perivascular adipose tissue accelerates injury-induced neointimal hyperplasia: role of monocyte chemoattractant protein-1. Arterioscler Thromb Vasc Biol 34: 1723-1730, 2014.

MARGARITIS M, ANTONOPOULOS AS, DIGBY J, LEE R, REILLY S, COUTINHO P, SHIRODARIA C, SAYEED R, PETROU M, DE SILVA R, JALILZADEH S, DEMOSTHENOUS M, BAKOGIANNIS C, TOUSOULIS D, STEFANADIS C, CHOUDHURY RP, CASADEI B, CHANNON KM, ANTONIADES C: Interactions between vascular wall and perivascular adipose tissue reveal novel roles for adiponectin in the regulation of endothelial nitric oxide synthase function in human vessels. Circulation 127: 2209-2221, 2013.

MILLS CD: M1 and M2 macrophages: oracles of health and disease. Crit Rev Immunol 32: 463-488, 2012.

OUWENS DM, SELL H, GREULICH S, ECKEL J: The role of epicardial and perivascular adipose tissue in the pathophysiology of cardiovascular disease. J Cell Mol Med 14: 2223-2234, 2010.

OWEN MK, NOBLET JN, SASSOON DJ, CONTEH AM, GOODWILL AG, TUNE JD: Perivascular adipose tissue and coronary vascular disease. Arterioscler Thromb Vasc Biol 34: 1643-1649, 2014.

REAVEN GM: Syndrome X: 6 years later. J Intern Med Suppl 736: 13-22, 1994.

REIFENBERGER MS, TURK JR, NEWCOMER SC, BOOTH FW, LAUGHLIN MH: Perivascular fat alters reactivity of coronary artery: effects of diet and exercise. Med Sci Sports Exerc 39: 2125-2134, 2007.

RITTIG K, STAIB K, MACHANN J, BOTTCHER M, PETER A, SCHICK F, CLAUSSEN C, STEFAN N, FRITSCHE A, HARING HU, BALLETSHOFER B: Perivascular fatty tissue at the brachial artery is linked to insulin resistance but not to local endothelial dysfunction. Diabetologia 51: 2093-2099, 2008.

SCHIPPER HS, PRAKKEN B, KALKHOVEN E, BOES M: Adipose tissue-resident immune cells: key players in immunometabolism. Trends Endocrinol Metab 23: 407-415, 2012.

SUGANAMI T, NISHIDA J, OGAWA Y: A paracrine loop between adipocytes and macrophages aggravates inflammatory changes: role of free fatty acids and tumor necrosis factor alpha. Arterioscler Thromb Vasc Biol 25: 2062-2068, 2005.

SZASZ T, WEBB RC: Perivascular adipose tissue: more than just structural support. Clin Sci (Lond) 122: 1-12, 2012. 
TIAN Z, MIYATA K, TAZUME H, SAKAGUCHI H, KADOMATSU T, HORIO E, TAKAHASHI O, KOMOHARA Y, ARAKI K, HIRATA Y, TABATA M, TAKANASHI S, TAKEYA M, HAO H, SHIMABUKURO M, SATA M, KAWASUJI M, OIKE Y: Perivascular adipose tissue-secreted angiopoietin-like protein 2 (Angpt12) accelerates neointimal hyperplasia after endovascular injury. J Mol Cell Cardiol 57: 1-12, 2013.

VAGUE J: La differentiation sexuelle, facteur determinant des formes de l'obesite. Presse Med 55: 339, 1947.

VERHAGEN SN, VINK A, VAN DER GRAAF Y, VISSEREN FL: Coronary perivascular adipose tissue characteristics are related to atherosclerotic plaque size and composition. A post-mortem study. Atherosclerosis 225: 99-104, 2012. 